\title{
Sciendo
}

DOI: $10.1515 /$ sspjce-2019-0011

\section{Inlet device with double exponential profile distributor for indoor air dispensation}

\author{
Florin Domnita ${ }^{1}$, Peter Kapalo ${ }^{2}$ \\ ${ }^{1}$ Technical University of Cluj-Napoca, Romania \\ Building Services Faculty, Department of Building Services Engineering \\ e-mail: florin.domnita@insta.utcluj.ro \\ 2 Technical University of Košice \\ Faculty of Civil Engineering, Institute of Architectural Engineering \\ e-mail: peter.kapalo@tuke.sk
}

\begin{abstract}
This paper presents a device for introducing air inside a room with the novelty of double-exponential profile of the distributor. This allows entering the rooms of large quantities of blow-in air with low velocities, with the result of possible use in locations with a high required air exchange. In the Laboratory of Ventilation and Air Conditioning of the Technical University of Cluj-Napoca, it was designed and built an experimental stand in order to investigate the velocity field of a double-equal strength (double exponential profile) inlet device for spatial air-distribution. There are presented the measurements that were performed in the laboratory in order to establish the velocity field and the spatial distribution of air. The proposed solution can be used in many applications to provide high rates of air through the ventilation systems.
\end{abstract}

Key words: inlet device, air velocity, jet, distribution, movement, double exponential, spatial.

\section{Introduction}

The main purpose of the inlet devices is to achieve ventilation effect by obtaining a proper distribution of the introduced air jet. Therefore, is necessary to use inlet devices that allow the introduction of a maximum rate of air into a room without exceeding admissible indoor air velocities in the occupied zone [1]. Several studies [2, 3, 4, 5, 6 and 7] are also focused with relevant results on similar issues, such as: air velocities in the occupied zone, indoor airflow shape and impact on indoor air quality of indoor air distribution.

This paper presents a device for introducing air with the novelty of double-exponential profile of the distributor. This allows entering the rooms of large quantities of blow-in air with low velocities, with the result of possible use in locations with a high required air exchange. 
Since the air distribution in mechanically ventilated rooms is determined for the most part (about $90 \%$ ) of air jets, it means that the current lines generated by air jets must provide appropriate ventilation effect primarily in the occupied zone [1]. A number of clean rooms ventilation solutions (e.g. operating theaters) recommended the use of large inlet air devices to enable the introduction of high rates of airflow with low primary air velocities values [8]. In this way it increases also the phenomenon of indoor air induction into the main stream of the inlet air jet.

In real situations, the current lines of the air jets are more or less influenced by other fields of air pressure created in natural or mechanical way by infiltrated or accidentally appeared air currents, by the presence of natural obstacles which are due to the presence of machinery, furniture, building components or the occupants themselves. Compare with this, both in theoretical studies and researches on experimental stands, it creates the conditions for free airflow evolution. It is considered that the air jet current lines are arising from the pole of the jet. Also, it must be taken measures to stabilize the airflow in the ventilation duct in the upstream section from the inlet device.

\section{Experimental stand and measurement apparatus}

The solution presented in this paper refers to a double exponential discharge device distributor, in order to ensure a flow of the inlet air jet as close as possible to the theoretical model of free isothermal jet [1].

For this purpose, in the Laboratory of Ventilation and Air Conditioning of the Technical University of Cluj-Napoca, is designed and built an experimental stand (see Figure 1 and Figure 2) for the measurement of the air velocity field of a double-equal strength (double exponential profile) inlet device for spatial air-distribution.

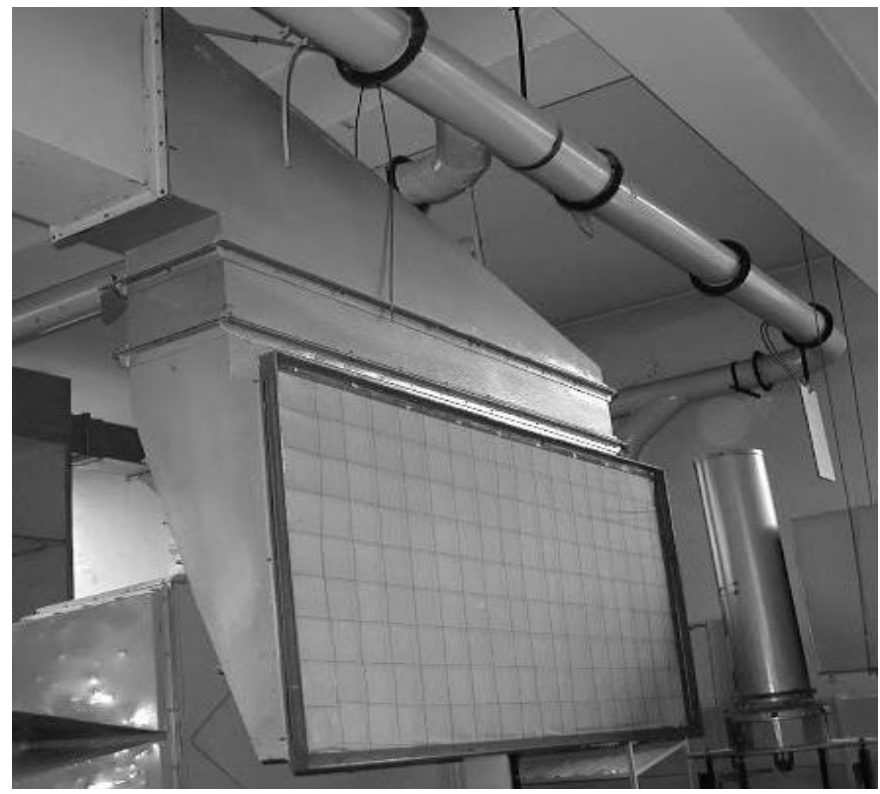

Figure 1: Stand for studying the air velocity field of the double-equal strength inlet device (doubleexponential profile) for spatial air-distribution. 
The airflow measurement apparatus is a digital thermo-anemometer (TA 35 type AIRFLOW) with high accuracy class $( \pm 0.01 \mathrm{~m} / \mathrm{s})$ and measurement range for air velocity from $0.05 \mathrm{~m} / \mathrm{s}$ to $25 \mathrm{~m} / \mathrm{s}$.

The stand is made of the following components (see Figure 2):

- A - simple-equal strength (simple exponential profile) inlet device, size: 900x1,800 $\mathrm{mm}$, fitted with adjustable blades to produce a uniform air distribution throughout the discharge plane;

- B - rectangular connecting duct with internal airflow stabilization blades, size: $300 \times 1,800 \mathrm{~mm}$, to achieve a plane-parallel airflow;

- C - distributor of simple-equal strength of the inlet device, size: 300x1,800 mm, to assure stationary plane-parallel airflow in the upstream section;

- D -rectangular bend $\left(90^{\circ}\right)$ with internal airflow stabilization blades;

- E - reducer from rectangular to circular section;

- V - mono-aspirant centrifugal fan with airflow rate $\mathrm{D}=4,375 \mathrm{~m}^{3} / \mathrm{h}$.

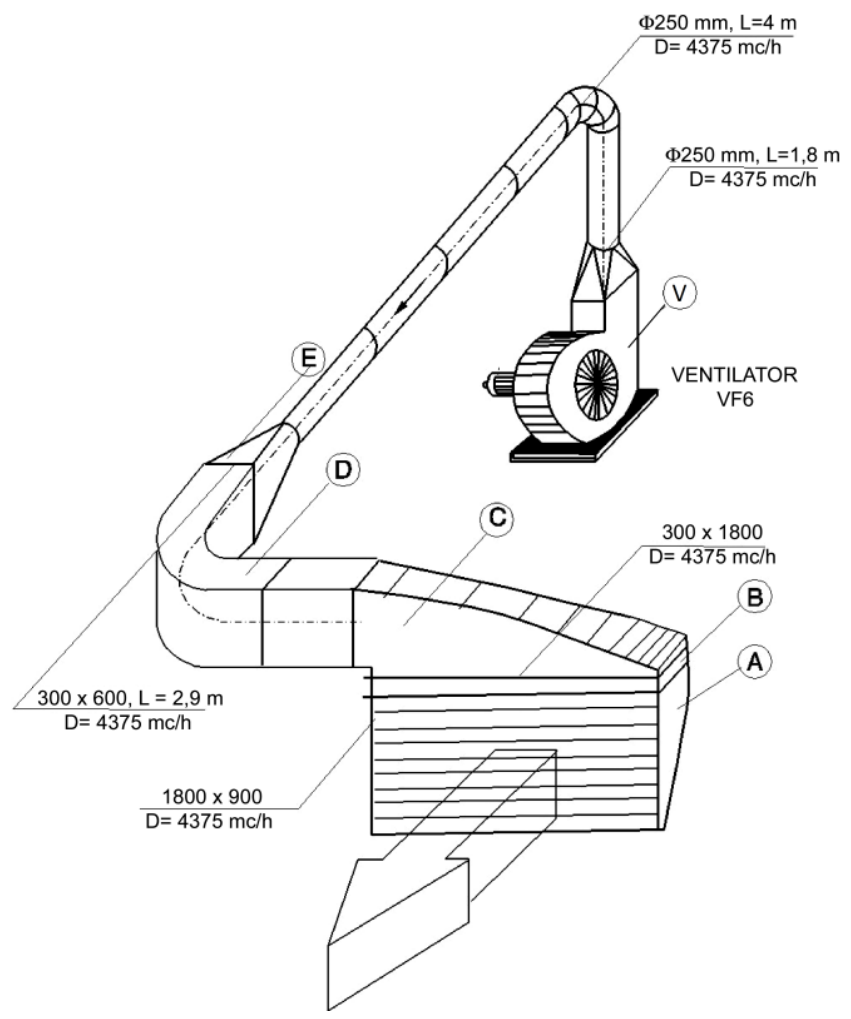

Figure 2: Stand for studying the air velocity field of the double-equal strength inlet device (doubleexponential profile) - Isometric drawing.

The whole inlet device is made of three main components: A, B and C.

The double-equal strength (double exponential profile) inlet device for spatial air-distribution was designed by applying twice (for horizontal and for vertical distribution) the equations which allow to calculate the dimensions of the two distributors with variable section [9], 
represented in Figure 2 by parts $\mathrm{A}$ and $\mathrm{C}$.

All inlet devices intend to supply air in the occupied area at values for velocity, temperature, humidity, concentrations of different pollutants that correspond to the comfort conditions in the room. These considerations lead to the value of the initial velocity in the discharge plane, noted with $\mathrm{v}_{0}$. To ensure the uniformity of ventilation, the air velocity is advisable to be as close to a constant value all over the discharge plane.

In this way, the initial velocity $\mathrm{v}_{0}$ in the discharge plan of the device will be constantly around $0,75 \mathrm{~m} / \mathrm{s}$, a value which corresponds to an easy physical activity. Due to the large size of the inlet device, it was necessary to provide airflow stabilization and control blades.

The air jet develops into a free space, which is not influenced by any disturbance surfaces or objects, so the measurements will not be at all affected.

\section{Measurements and processing results}

The investigation of the air velocity field of the double-equal strength inlet device (doubleexponential profile) involves measuring the values of air velocity with an apparatus that does not influence the course of the current lines through both specialized transducer dimensions and the manner of making measurements [10].

There were performed a sufficient number of measurements, with enough equipment accuracy, to provide accurate values of air velocity into the air jet streams [10].

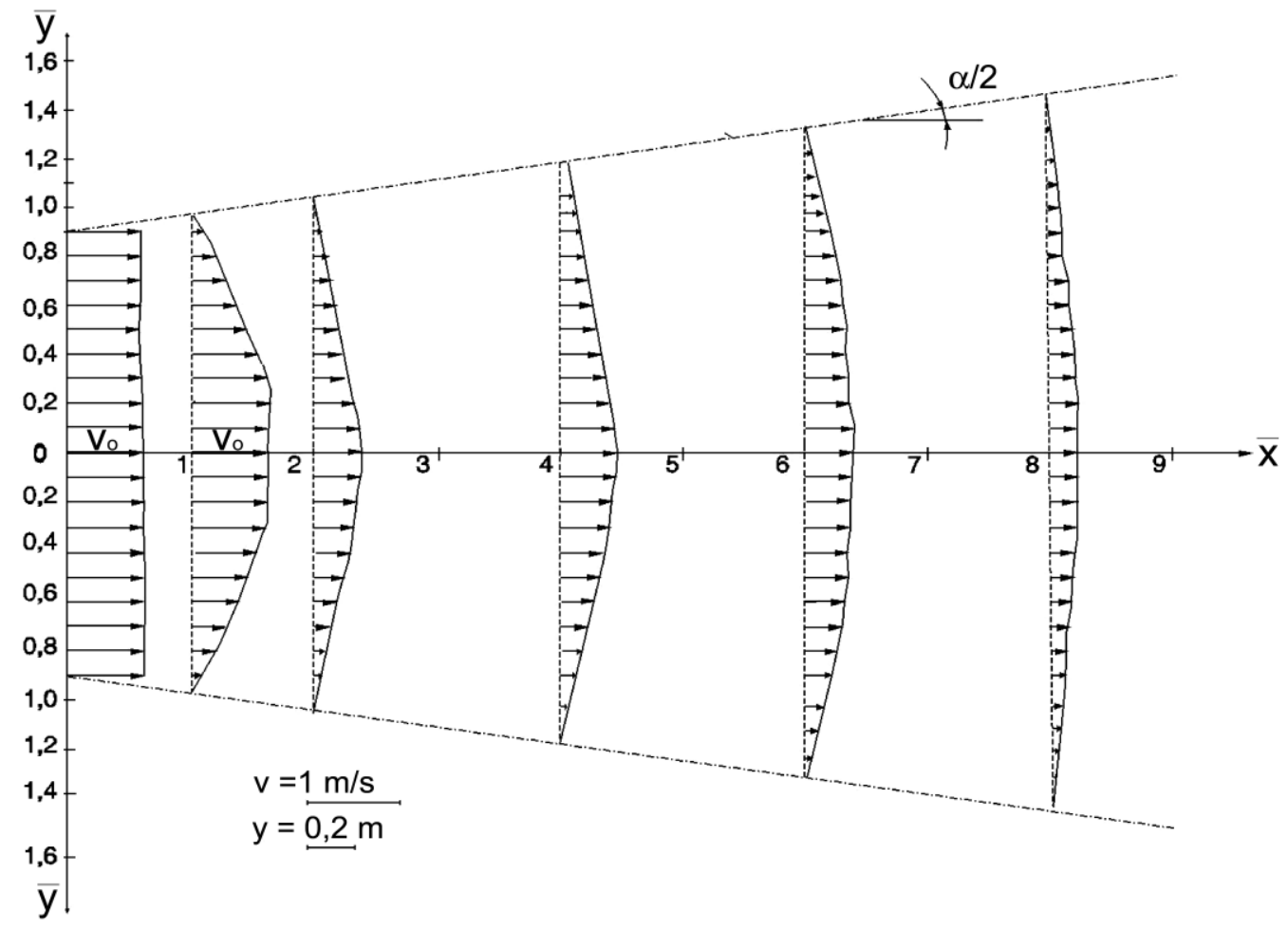

Figure 3: Air velocity hodographs measured in horizontal plane.

To measure the air velocities along the jet, in perpendicular planes to the jet axis, at different 
distances (noted with $\mathrm{x}$ ) from the discharge plane, is using a classical method that uses, for keeping the same measurement points along the jet, a roller grid with square mesh [10]. Measuring transverse planes of the air velocity field have been predetermined by the rectangular roller grid with dimensions of $3000 \times 1500 \mathrm{~mm}$ and with $100 \times 100 \mathrm{~mm}$ square mesh. The measuring grid was placed successively at predetermined distances from the plane of discharge, beginning with the distance $\mathrm{x}=0 \mathrm{~m}$ (discharge plane) and finishing at the distance where axial air velocity is $0.25 \mathrm{~m} / \mathrm{s}$. Measured velocities were noted in all the nodes of the grid [10], resulting the air velocity hodographs in two perpendicular planes: one, horizontal and the other one, vertical (see Figure 3 and Figure 4) [8], [10].

In preparation for developing the mathematical model of the spatial air jet, it was chosen the dimensionless mode of expression of geometric and kinematic quantities. Thus, the measurements were made at dimensionless distances: $\bar{x}=0, \bar{x}=1, \bar{x}=2, \bar{x}=4, \bar{x}=6$ and $\overline{\mathrm{X}}=8$, resulting the hodographs of air velocities in two perpendicular planes (see Figure 3 and Figure 4). The expression of dimensionless distances is: $\bar{x}=\frac{x}{d_{0}} \quad\left(d_{0}=\frac{2 \cdot a \cdot b}{a+b}-\right.$ equivalent diameter of the rectangular inlet device with dimensions a and $b$ ).

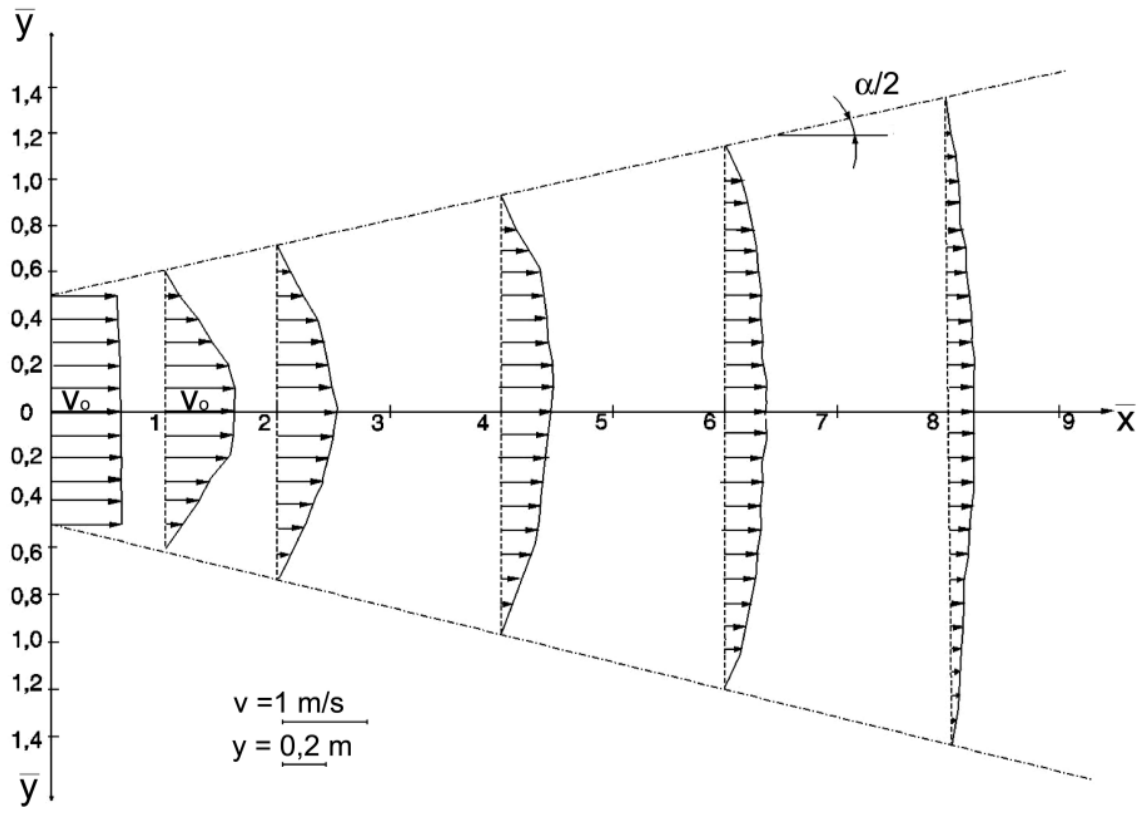

Figure 4: Air velocity hodographs measured in vertical plane.

After the air comes out the discharge device, enter into a stagnant air environment. As the air jet moving mass advances, due to induction, an amount of increasingly higher of stagnant air join to the moving air. In this way, the initial air jet kinetic energy is gradually consumed, decreasing the speed of air movement.

The hodographs of air velocities have changed from rectangle (in the discharge plane) to curvilinear trapezoid, respectively curvilinear triangle with the growth of distance [8]. The configuration of the isokinetic curves highlights the shape of the air jet. This represents a greater approach to the free, round, isotherm air jet [1]. This is also explained by the ratio 1:2 between the sides of the discharge device. 


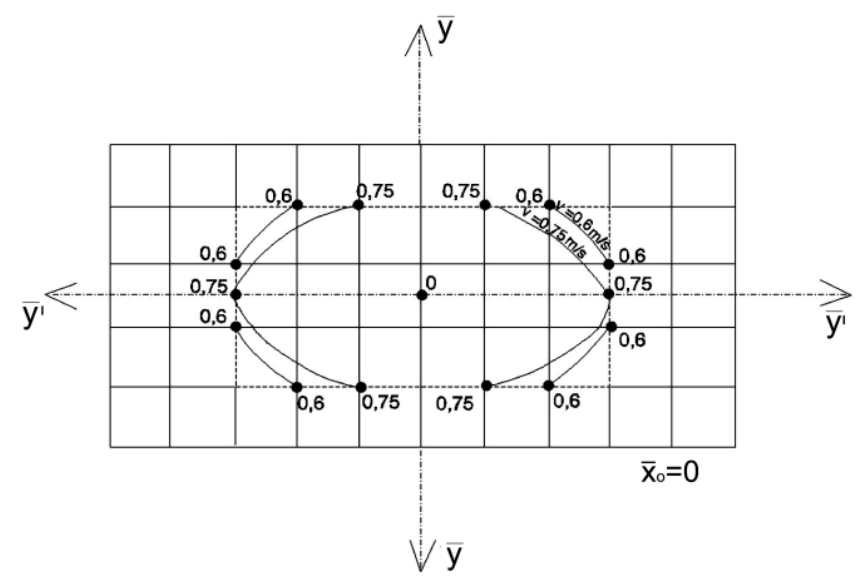

Figure 5: Isokinetic curves for $\overline{\mathrm{X}}=0$.

Based on the measured air velocities in the grid nodes, isokinetic curves were drawn (see Figure 5, Figure 6, Figure 7, Figure 8, Figure 9 and Figure 10).

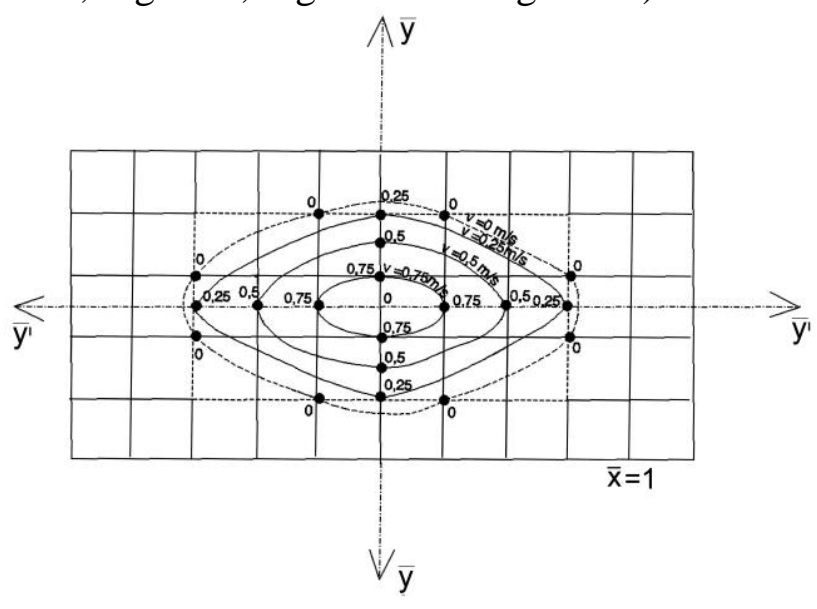

Figure 6: Isokinetic curves for $\overline{\mathrm{X}}=1$.

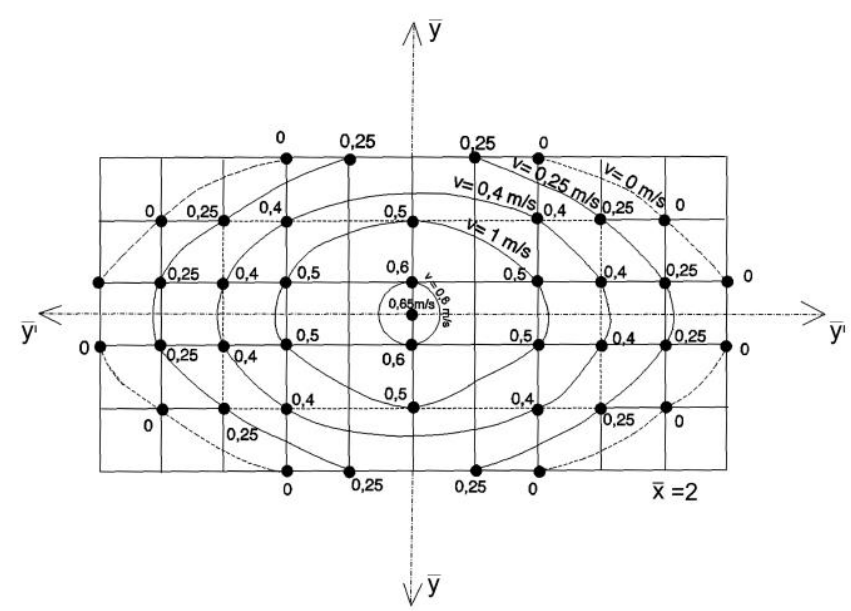

Figure 7: Isokinetic curves for $\overline{\mathrm{X}}=2$. 


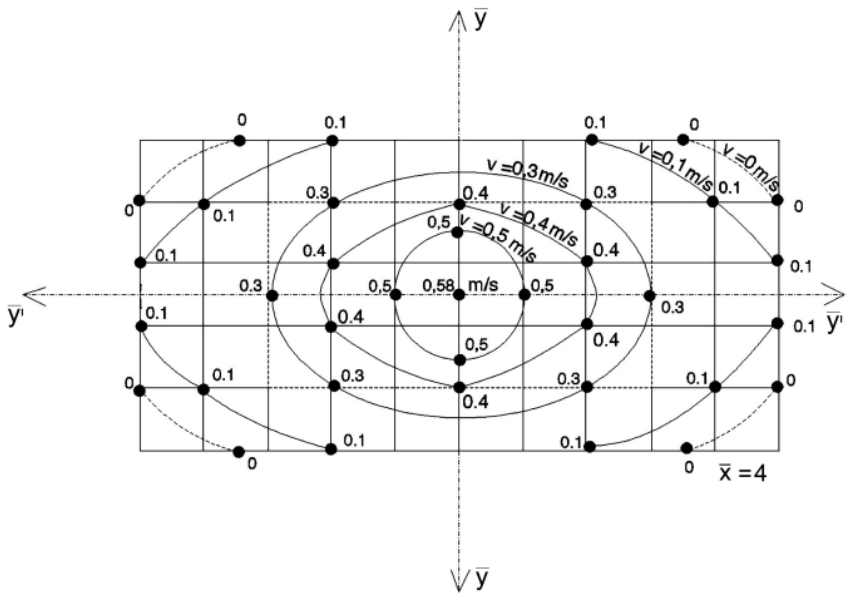

Figure 8. Isokinetic curves for $\overline{\mathrm{X}}=4$.

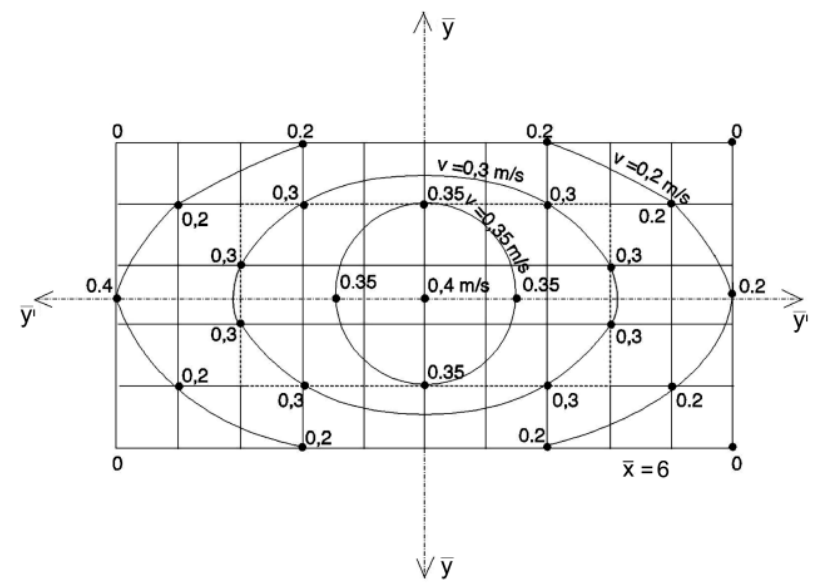

Figure 9: Isokinetic curves for $\overline{\mathrm{X}}=6$.

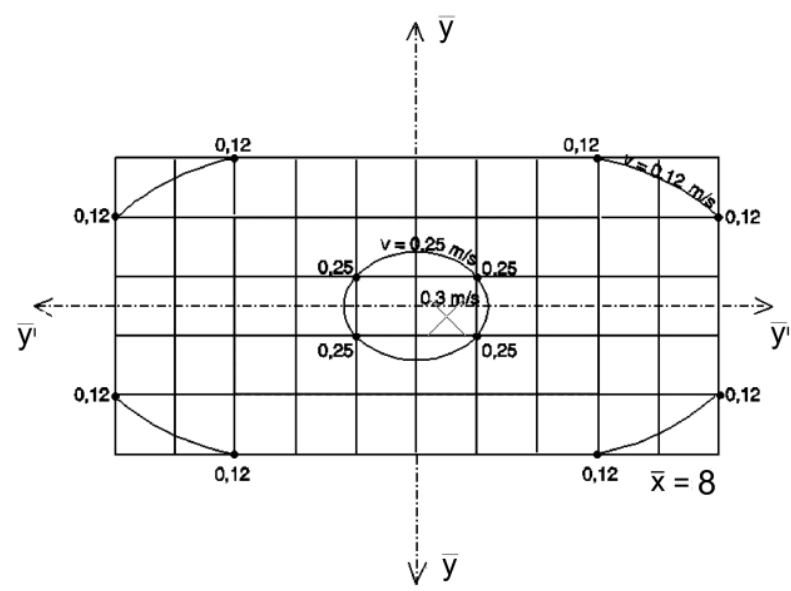

Figure 10: Isokinetic curves for $\overline{\mathrm{X}}=8$. 
The air velocities hodographs form revealed the air jet envelope and angle of divergence, which depends on the initial airflow rate. The result is a divergence angle of the air jet $\alpha$ of about $32^{\circ}$ and a dimensionless air jet throw equal with 9 .

These curves also highlighted the three areas of this type of air jet, with the following lengths:

- initial sector $\mathrm{X}_{1}=1.4 \mathrm{x} \mathrm{d}$;

- transition sector $\mathrm{X}_{2}=1.2 \times \mathrm{d}_{0}$;

- main sector $\mathrm{X}_{3}=6.4 \mathrm{x} \mathrm{d}_{0}$.

The air velocity hodographs confirmed the increase of airflow rate in the air jet with the distance to the discharge plane [11]. Accepting the theory of similarity, the measurements that were made will allow establishing a mathematical model of these air supply system through a large inlet area [11]. In this order, we will apply the classical method of calculation the jets characteristic elements that use the dividing the variable elements along the jet to the constant elements from the device discharge plan, resulting dimensionless variables [1]. The results will be presented as dimensionless variables in order to ensure that this can be generalized and easily applied to other values of airflow rates or other dimensions of inlet devices.

\section{Conclusion}

This type of air jet presents a compact enlargement with a divergence angle of $32^{\circ}$, a dimensionless air jet throws equal with 9 and an induction factor appropriate for a satisfactory ventilation effect [12].

The double-equal strength inlet device (double-exponential profile) provides relatively uniform air velocities in any perpendicular measurement planes of the air jet stream. Thus, the proposed solution can be used to provide ventilated air in many applications. Also, the large range obtained for air velocities lead to a great flexibility in operations for this kind of devices.

Following the evolutionary stage of inlet air devices, able to achieve enhanced ventilation effects, the designed and executed stand has some advantages:

- Provides a controlled airflow, close to laminar airflow conditions;

- Provides to the ventilated room an approximately constant air quality, appropriate for indoor environment demanded comfort;

- Ensures investment, execution and exploitation costs at reasonable values;

- Assures a good opportunity of harmonization with interior design elements;

Provides the possibility of directing the air jet, where it requires, towards certain areas that require greater conditioned air airflow.

\section{Acknowledgements}

This article was elaborated in the framework of the project VEGA 1/0697/17.

\section{References}

[1] Popovici, T. Instalaţii de ventilare si condiţionare - in Romanian (Ventilation and air conditioning systems), Volume 1, Cluj-Napoca, U.T.PRESS, 2010.

[2] Janbakhsh, S., Moshfegh, B. - Experimental investigation of a ventilation system based on wall confluent jets, Building and Environment, Volume 80, 2014, p. 18-31, ISSN 0360-1323, 
https://doi.org/10.1016/j.buildenv.2014.05.011.

(http://www.sciencedirect.com/science/article/pii/S0360132314001474)

[3] Ansari, A., Chen, K.K., Burrell, R.R. et al. Effects of confinement, geometry, inlet velocity profile, and Reynolds number on the asymmetry of opposed-jet flows. Theor. Comput. Fluid Dyn. 32, p. 349-369 (2018) doi:10.1007/s00162-018-0457-1

[4] Cao, X., Li, J., Liu, J., Yang, W. 2D-PIV measurement of isothermal air jets from a multi-slot diffuser in aircraft cabin environment, Building and Environment, Volume 99, 2016, p. 44-58, ISSN 0360-1323, https://doi.org/10.1016/j.buildenv.2016.01.018. (http://www.sciencedirect.com/science/article/pii/S0360132316300191)

[5] Hurnik, M., Blaszczok, M., Popiolek, Z. - Air distribution measurement in a room with a sidewall jet: A 3D benchmark test for CFD validation, Building and Environment, Volume 93, Part 2, 2015, p. 319-330, ISSN 0360-1323, https://doi.org/10.1016/j.buildenv.2015.07.004. (http://www.sciencedirect.com/science/article/pii/S0360132315300524)

[6] Voznyak, O., Korbut, V., Davydenko, B., Sukholova, I. Air distribution efficiency in a room by a two-flow device (2020). doi:10.1007/978-3-030-27011-7_67 Retrieved from www.scopus.com

[7] Voznyak, O., Sukholova, I., Myroniuk, K. Research of device for air distribution with swirl and spread air jets at variable mode. Eastern-European Journal of Enterprise Technologies, 6(7), p. 15-23. (2015). doi:10.15587/1729-4061.2015.56235

[8] Domniţa, F. V. Contribuţii privind decontaminarea si condiţionarea aerului în spitale - in Romanian (Contributions regarding ventilation and air decontamination in hospitals), $P d . D$. Thesis, Cluj-Napoca, 2003, p. 26-80

[9] Niculescu, N., Stoenescu, P., Duţă, G., Colda, I. Instalaţii de ventilare şi climatizare. in Romanian (Ventilation and air conditioning systems), EDP Bucharest, 1982

[10] Sandberg, M. Measurement technics in room airflow. ROOMVENT Proceedings. Warsaw, 1994, p.345-349

[11] Chen, Q. Prediction of room air motion by Reynolds-Stress models. Buiding and Environment, Vol. 31, 1996, p.278-285

[12] Hanzawa, H., Melikow, A. K. Airflow characteristics in the occupied zone of ventilated spaces. ASHRAE Transactions 102/2007, p.411-417 